Commentary

\title{
The optical-coenaesthetic disproportion in feeding and eating disorders
}

\section{Introduction}

In our culture, imbued social and cultural practices permeated by the hegemony of vision over the other senses [1], the predominance of sight is claimed to affect self-experience and self-understanding. An analogous tendency to attend those aspects of one's own bodily self that are matters of public display, namely its exterior aspect, rather than to more covert aspects, e.g. bodily sensations, emotional feelings and privately held beliefs about oneself, also affects persons with a diagnosis of feeding and eating disorders (FED). In these persons, the dialectical proportion between the optically- and the coenaesthetically-apprehended body is flawed. Their possibility to feel themselves coenaesthetically is weakened or threatened by coenaesthopathic and emotional paroxysms. These persons feel extraneous from their own body and their bodily feelings are discontinuous over time. Next to this troubled coenaesthesia, and as a compensation to it, persons with FED experience their own body as an object that is looked at by the other persons [2-6]. Their body is principally given to them as an object 'to be seen'. It is a body exposed and subjected to the Other's gaze and thus reduced to its appearance.

\section{Three forms of embodiment}

First and foremost, the way we experience our body is the outcome of the dialectics between coenaesthesia and sight. Bodily experience is not only influenced by the way we feel ourselves, but also by the way we feel looked at by the others. It is a combination of the way we feel ourselves from a first-person perspective and the way we see ourselves from a third-person perspective. This is a way to transcend our private and idiosyncratic apprehension of ourselves.

In order to determine the kind of disorder of embodiment that characterizes people with FED we need a preliminary distinction between the subject-body as experientially different from the object-body [7,3]. With 'subject-body' we designate the coenaesthetic apprehension of one's own body - the primitive experience of oneself as a spatiotemporal embodied agent in the world, the basic form of self-awareness. With 'object-body' we indicate the body thematically investigated as an entity existing in the outside world, as for example by the natural sciences as anatomy and physiology, or perceived from without, as for instance when I look at myself in a mirror. Whereas the experience of my subject-body is a direct, unmediated apprehension of it in the first-person perspective, neither a representation of it mediated by reflection (as the case with 'body image'), nor the perception of my body as an external entity separated from myself; I experience my object-body in the thirdperson perspective. Sight is the sense modality through which I perceive my body as an object-body, whereas the modality by which I apprehend my body as subject-body is called coenaesthesia.

In addition to these two dimensions of embodiment (subjectbody and object-body) one can apprehend one's own body also from another vantage point, i.e. as one's own body when it is looked at by another person [8]. In this kind of bodily experience, otherness is centre stage. When I become aware that I, or better my own body, is looked at by another person, I realize that my body can be an object for that person. This experience differs both from feeling one's body coenaesthetically (subject-body) and from perceiving it from without as an object out there seen with my own eyes (objectbody). It consists in feeling my own body from within, but as an object being looked at by the Other (body-for-Others).

As the first-person apprehension of my body is based on coenaesthesia, whereas its apprehension through the Other is based on the sense of sight, we may call this dynamic balance between experiencing one's body through coenaesthesia and through the Other's look the optical-coenaesthetic proportion - a prerequisite for constructing a safe and dependable sense of bodily self and personal identity.

\section{Negative effects of being looked at by another: shame and reification}

Feeling looked at by another can be experienced as threatening. It is not that the Other is threatening me with bodily harm - the Other's look is not a threaten to physical integrity, but rather to selfhood and identity and to the arrangement of my world.

When I feel looked at by the Other, all of a sudden the world comes on to me differently. It is no longer comfortably arranged around my point of view, but around the Other's vantage. The values and meanings that appear in the world are suddenly his meanings and values. I feel judged by the Other's look. I may feel ashamed or proud, and those feelings reflect the Other's meanings and values. Yet, although the Other's look indicate his judgements, I recognize myself in the Other's look. His look defines me, it cuts me to the core.

Among the responses a person may have when being looked at, the experience of being objectified and fixed by the look of another appears to be particularly relevant. First and foremost shame for 
feeling disapproved is the emotion at play. Shame is the emotion whereby I am aware of being seen by another person whose devaluating gaze and annihilating contempt uncovers a part of who I am, usually a part that makes me feel inadequate and dishonoured. The feeling of shame derives from the fact that experiencing my body as an object seen by another person reduces my body to mere anonymous matter. I feel deprived of the power of imagination, that is divested of what I could imagine and desire to do with my 'facticity' - the 'whatness' of my body [9]. Feeling objectified and fixed by the Other's look entangles me in a negative bond that makes me feel that I have lost (at least) part of my freedom. The objectification by the Other's look is experienced as the 'negation' of my freedom, that is the negation of my capacity to transcend the mere objective entity that I feel I am when seen by the Other. When I feel looked at by the Other I also feel the negation of my possibility to imagine to be 'something else' than the 'what' or 'mere object' I am. The power of the look of the Other may produce a unbalance between the 'I-am' and the 'I-can'.

\section{Positive effects of the other's gaze in persons with fed}

It is not always shame, negation of freedom and fixation on 'whatness' that take place when they feel looked at by other persons. In persons with FED, feeling one's body as an object being looked at by another has a twofold effect. On the one hand, it makes them feel embarrassment and repulsion for their own body. But on the other hand it helps them recover a sense of selfhood, 'unity' and 'condensation' [2].

This phenomenon is epitomized by the following micronarratives [6]: 'The way I feel depends on the way I feel looked at by the Others', 'Sometimes I focalize myself through the gaze of the Others', 'For me it's very important to see myself through the eyes of the others', 'When I meet someone I can't stay without knowing what he thinks of me', 'Even if I think that the way the others evaluate me is wrong, I can't do without it'. These sentences are representative of the IDEA subscale 'Feeling oneself through the gaze of the other and defining oneself through the evaluation of the other' [3-5] showing that persons with FED are concerned with public self-consciousness, as opposed to private self-consciousness, which includes all those qualities of the self that are formed in other people's eyes. This suggests that the Other's look is not only a source of intimidating and shameful 'negation' of their capacity to transcend their facticity or mere objective corporeality, but also a longed-for device through which they can finally define themselves - an optical self-prosthesis.

Last but not least, the Other's look can also help to solve or attenuate the anxiety that is caused by the conflict between 'being' and 'appearing'. Should one define oneself on the basis of what one feels, the self-feeling of oneself? Or else should one rely on the way one appears to the Others and on the Others' recognition? - is a common theme of interrogation, specially during adolescence. Being a body-for-Others and defining oneself through the Others' gaze is a solution, although a Gordian solution, of this perennial source of tension and uncertainty.

\section{Conclusions}

We normally experience our own body in the first- and thirdperson perspectives, as a body-subject felt from within and as a body-object seen from without. We also apprehend our body as an object being looked at by Others. Under normal conditions, the constitution of our own body, and consequently of our own self and identity, depends on the dialectic balance and integration between coenaesthetic and optical perspectives - the optical-coenaesthetic proportion.

In persons with FED, the optical-coenaesthetic proportion is flawed. Clinical evidence is available supporting the hypothesis that the coenaesthetic apprehension of oneself is troubled, and as a compensation to it, persons with FED experience their own body as an object that is looked at by the Other. Their body is principally given to them as an object 'to be seen'. It is a body exposed and subjected to the Other's gaze and thus reduced to its appearance. The Other's look serves as an optical prosthesis to cope with hypo- and dis-coenaesthesia and as a device through which persons with FED can define themselves and attenuate the anxiety produced by the conflicts between being-oneself and being-for-Others.

\section{References}

[1] Jay M. Downcast eyes: the denigration of vision in twentieth-century French thought. University of California Press; 1994.

[2] Stanghellini G. For an anthropology of eating disorders. A pornographic vision of the self. Eating and weight disorders-studies on anorexia. Bulim Obes 2005;10 (2):21-7.

[3] Stanghellini G, Castellini G, Brogna P, Faravelli C, Ricca V. Identity and eating disorders (IDEA): a questionnaire evaluating identity and embodiment in eating disorder patients. Psychopathology 2012;45:147-58.

[4] Stanghellini G, Trisolini F, Castellini G, Ambrosini A, Faravelli C, Ricca V. Is feeling extraneous from one's own body a core vulnerability feature in eating disorders? Psychopathology 2014;48(1):18-24.

[5] Stanghellini G, Mancini M, Castellini G, Ricca V. Eating disorders as disorders of embodiment and identity. Theoretical and empirical perspectives. In: McBride Hillary L, Kwee Janelle L, editors. Embodiment and eating disorders. Theory, research, preventions and treatment. London: Routledge; 2018. p. 127-42.

[6] Stanghellini G, Mancini M. The therapeutic interview. Emotions, values, and the life-world. Cambridge: Cambridge University Press; 2017.

[7] Husserl E. Ideen zu einer reinen Phaenomenologie und phaenomenologische Philosophie. II. Phaenomenologische Untersuchungen zur Konstitution. Den Haag: Nijhoff; (1912-1915).

[8] Sartre JP. Being and nothingness. New York: Washington Square Press; (1943/ 1992).

[9] Gennart M, Vannotti M. Corps et histoire de vie: La maladie chronique: un défi pour les soignants et les proches. Fabert; 2017.

Giovanni Stanghellini ${ }^{\mathrm{a}, \mathrm{b}, *}$ ${ }^{a}$ Department of Psychological, Humanistic and Territorial Sciences, 'G. d'Annunzio' University, Chieti, Italy

${ }^{b}$ 'D. Portales' University, Santiago, Chile

* Corresponding author at: Department of Psychological, Humanistic and Territorial Sciences, 'G. d'Annunzio' University,

Chieti, Italy.

E-mail address: giostan@libero.it (G. Stanghellini).

Received 9 February 2019

Available online 2 March 2019 